\title{
Mechanistic Knowledge and Public Opinion of GMOs
}

\author{
Allison Haskell ${ }^{1 *}$
}

\begin{abstract}
This study explores how mechanistic learning affects participants' knowledge and opinions of GMOs, as well as retention of knowledge and opinions. Two surveys were distributed to UNT, undergraduates before and after they read an informational passage on the process of genetic modification and recent research on GMO safety. Responses to multiple choice and free response questions allowed insight into their knowledge and opinions of GMOs. This study was predicated upon a study at University of California-Berkeley that used mechanistic knowledge to educate participants about the issue of climate change. Like the climate-change study, participants' knowledge increased after reading the informational passage, and they were more accepting of GMOs even several days after reading the passage. Together, these studies indicate that mechanistic knowledge is a useful tool for educating the public on controversial, scientific issues.
\end{abstract}

\section{Keywords}

GMOs - Mechanistic Knowledge - Science Education

${ }^{1}$ Department of Biological Sciences, University of North Texas

*Faculty Mentor: Dr. Lindsay Moore

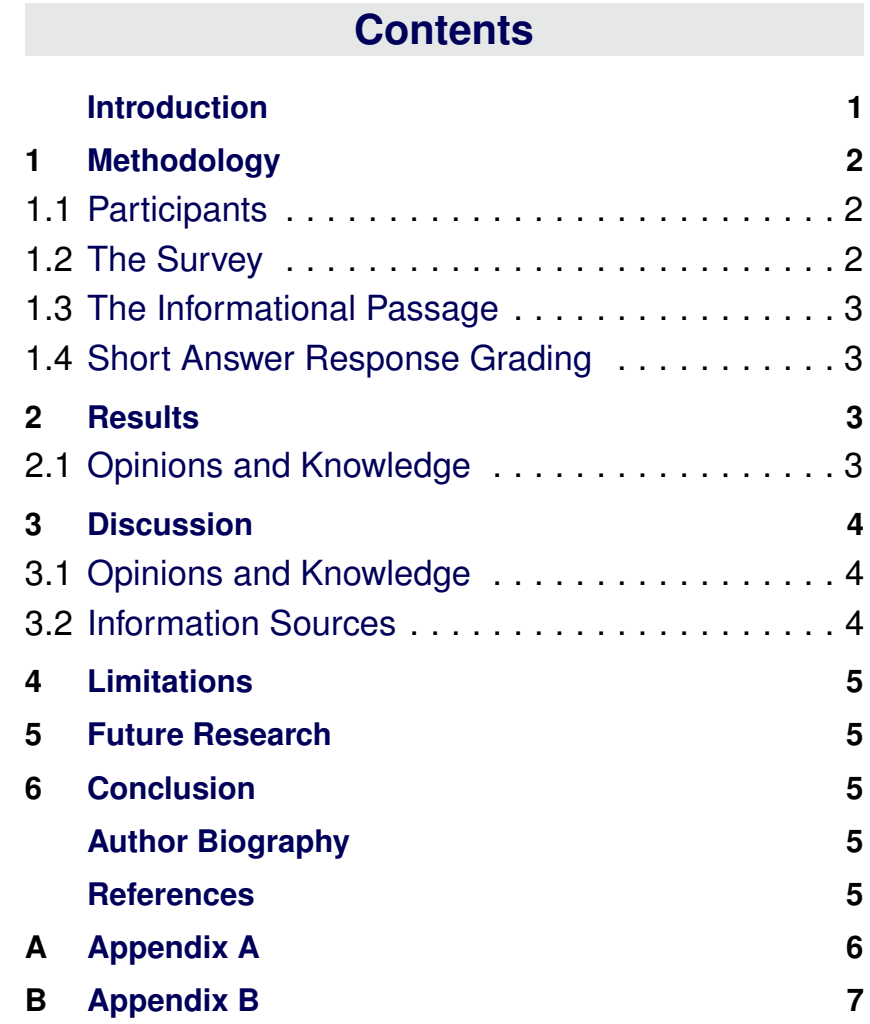

\section{Introduction}

For many people, learning math and science is something they learn in high school and think they will never use again; however, science literacy is much more important than memorizing facts. Critical thinking skills and a basic understanding of science are important skills that allow educated adults to make responsible decisions. Science influences the public's lives on a daily basis. People frequently face science-based decisions - from voting on policy to the nutritional value of grocery shopping $[1,2]$. Furthermore, government funding relies on the general public's having necessary knowledge to make decisions about funding. Still, in 2008 only $25 \%$ of Americans were considered scientifically literate[3,4], and even in 2013 American students were scoring below average in math and science literacy for developed countries [5].

This gap in knowledge between the scientific community and the general public has had startling consequences; for example, insufficient public education in New Orleans about disaster preparedness led to reductions in funding for levees. When the levees broke during Hurricane Katrina, over a thousand lives were lost [6]. Another example is the anti-vaccination movement. The movement started when Andrew Wakefield published a study in the Lancet that linked the measles, mumps, and rubella (MMR) vaccine to autism [7]. The Wakefield study was later retracted [8], but the antivaccination movement is still prevalent; putting children at risk for deadly diseases. Another prevalent example of ineffective science communication exists in the ongoing climatechange debate. Despite the scientific consensus that the earth's climate is warming [9], many people, including the President of the United States, still deny the existence of man-made climate change. Since so many people still deny climate change, laws to slow the effects of climate change take longer to pass and implement. According to Pew Research, 20\% of Americans believe there is no solid evidence that climate change is taking place [10]. As sea levels rise, "coastal residents denying climate change may be complicit in their land becoming seabed" [11]. The public and the scientific community need to 
form a united front to tackle such scientific issues effectively. Similarly, with GMOs the public must understand the science for new technologies to be implemented effectively.

There is a gap between what the public and the scientific community think about relevant scientific issues. In a Pew Research Center survey only $37 \%$ of the public believe GMOs are safe to consume, while $88 \%$ of American Association for the Advancement of Science (AAAS) members believe Genetically Modified Organisms (GMOs) are safe to consume [12]. Recent research published by the National Academies of Sciences Engineering and Medicine (2016) supports that GMOs are safe to consume. It is pertinent to address this gap in order to prevent problems such as the broken levees, the anti-vaccination movement, and the ongoing climate-change debate. At the same time, the gap in knowledge is not limited to Americans. On a global scale, many developing countries have resisted the introduction of GMOs, perhaps suggesting a lack of understanding of the risks and benefits of GMOs [13]. For example, Europe has been slow to adopt GMOs due to scientific uncertainty and consumer distrust [14]. The public must be scientifically literate to make responsible decisions. It is particularly important to ensure that adults are scientifically literate because they are responsible for laying the educational and political groundwork of the next generation.

Enhancing public understanding of science through improved outreach may be the key to getting the public onboard with modern science. Studies have shown that evidence-based outreach and education can help bridge the gap in knowledge between scientists and the public. Currently, several universities have programs that focus on public outreach. For example, WorldTAP (World Technology Access Program), a program at Michigan State University (MSU), offers training and education in areas such as agricultural biotechnology [13]. HungerU is a program from the Farm Journal Foundation that focuses on educating the public about food security and the use of agriculture biotechnology. The study found that after attending HungerU, students were more accepting of GMOs even without explicitly learning about their use [15]. Oregon State University (OSU) has a program to engage graduate and undergraduate students with K-12 schools around the state. The program includes National Science Foundation grant-funded fellows, a class, and a club devoted to K-12 outreach. They found that both the college and K-12 students benefited from the interaction. The K-12 students felt that a college education was more attainable after they had interacted with OSU students and the OSU students developed valuable communication skills [16].

This paper explores the use of evidence-based, mechanistic knowledge to educate the public. Mechanistic knowledge is the explanation of the process by which something happens. Ranney and Dav found that "mechanistic global warming knowledge causes greater global warming acceptance" [11]. This study was used as a model to study the effectiveness of using mechanistic knowledge to educate the public on GMOs.

\section{Methodology}

\subsection{Participants}

Using Ranney and Dav's climate-change study as a model, we developed two online surveys to distribute to volunteer student participants [11]. Instructors in the English and Technical Communication departments at the University of North Texas encouraged their students to participate in the study. These departments were selected to obtain a diverse group of students. 164 responses $(n=164)$ were obtained from the first survey, and $141(n=141)$ responses were obtained for the second survey. Forty-six percent of participants were in their first year of college, and $54 \%$ were upperclassman. Sixty-four percent were between the ages of 18 and 20, and 6\% were 27 or older. Over half were STEM (Science Technology Engineering and Mathematics) majors with $7 \%$ humanities students, $9 \%$ being business students, and $20 \%$ selected "Other". On a scale from 1 (being very liberal) to 9 (being very conservative), $40 \%$ were left-leaning (in the 1 and 4 range on the Likert scale) while $40 \%$ identified as being in the middle ( 5 on the Likert scale), and $25 \%$ identified as right-leaning (in the 6 to 9 range on the Likert scale). Sixty-seven percent of participants identified as being religious (not atheist/agnostic): the largest category of those identified as Christian (34\%), and $32 \%$ of participants identified as atheist/agnostic.

\subsection{The Survey}

Two surveys were administered to participants. The first one tested participants' knowledge and opinions of GMOs before and after they read a 400-word informational passage. The passage described the process, or mechanism, of the genetic modification process as well as recent research concerning GMO safety [17]. Students received basic instructions about the study and were provided with a link to the first survey on the university's e-learning platform for 48-hours. The pretest part of the survey included a demographics section; 10 multiple choice- and one free- response question to gauge participants' knowledge of GMOs; 3 questions regarding news consumption; and 9 Likert-scale questions concerning participants' opinions of GMOs. The next section of the survey included the 400-word passage. Immediately following the passage was a posttest: it included 5 questions about the subjects' reactions to information in the passage, and their response to identical questions from the pretest. The goal was that of determining whether the subjects' knowledge and/or opinions about GMOs had changed.

To assess retention of participants' knowledge, we administered a second survey. A link to the second survey was posted 3-5 days after the posting of the first survey. The second survey included the same 3 multiple choice and free response questions assessing participants' knowledge, as well as the same 9 Likert-scale opinion questions from before and after the reading in the first survey. Both surveys can be found in the supporting materials section. 


\subsection{The Informational Passage}

The goal of the passage was to provide a solid foundation of scientifically accurate information upon which participants could form their own opinions. Using the Ranney and Dav's study as a model, we constructed a 400-word explanation, 35-word summary, and a 50-word summary of the genetic modification process. A 400-word passage was used because previous studies found that short explanations consisting of approximately 400 words appeared greatly to increase knowledge $[18,11]$. To ensure accuracy of the information in the passage, professors in the Department of Biological Sciences at UNT were consulted.

The 400-word explanation started with a brief history of genetic modification. The process of genetic modification was then described using information from the University of Nebraska-Lincoln Institute of Agriculture and Natural Resources Crop Watch page. The Crop Watch page uses games, graphics, and brief descriptions to teach readers how genetically modified crops are made. This page breaks down the process into five steps, which were summarized in the informational passage. After describing the process, we referenced the most recent and comprehensive publication on GMOs as evidence that there are no harmful side effects from consuming GMOs [17]. In addition, the Golden Rice Humanitarian Board was cited to provide additional background information regarding the purpose of GMOs. The passage from the survey can be found in Appendix A.

\subsection{Short Answer Response Grading}

Each short-answer response regarding participant's knowledge of the process of genetic modification was manually graded using a 1-4 numerical grading system. Responses were originally classified as 1 - "probably do not know", 2 - "somewhat knows", 3 - "probably knows", and 4 - "definitely knows how GMOs are made." Groups 1 and 2, and 3 and 4 were then combined into the two categories: "Do not understand" and "Somewhat understand," as shown in Figure 1. This code enabled researchers to identify patterns in participants' knowledge before and after reading the passage. The grading rubric can be found in Appendix B.

\section{Results}

\subsection{Opinions and Knowledge}

This study found that participants gained knowledge about how and why GMOs are made. Figure 4 shows that $92 \%$ of participants stated that at least some of the information in the passage was new to them. The largest category, $31 \%$, stated that a moderate amount was new to them and $10 \%$ stated that a great deal was new to them. Figure 1 shows data from freeresponse questions asking participants to explain the process of genetic modification. Each response was manually read and graded using a rubric that can be found in Appendix B. The rubric assigned responses with numbers 1-4 as described in detail in the Methodology section. Qualitative observations during the grading process revealed a clear split between
Participants' knowledge of how GMOs are made

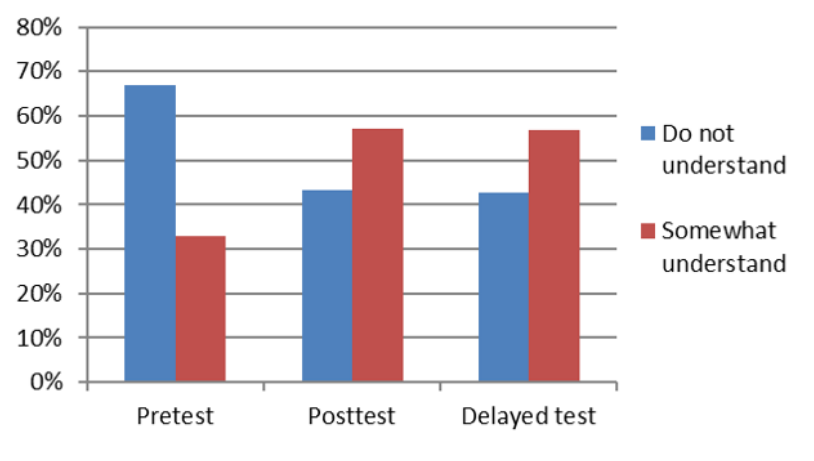

Figure 1. Participants' knowledge of how GMOs are made

participants who somewhat understood the process and those who did not. For example, the response "GMOs are made by improving the selected trait via scientific methods" was assigned a 1 - "probably do not know" because it does not show that the respondent understands the process of genetic modification. On the other hand, the response "Via selective breeding and through genetic manipulation in order to create or acquire positive traits" was assigned a 3 - "probably knows" because the key word "genetic manipulation" is mentioned.

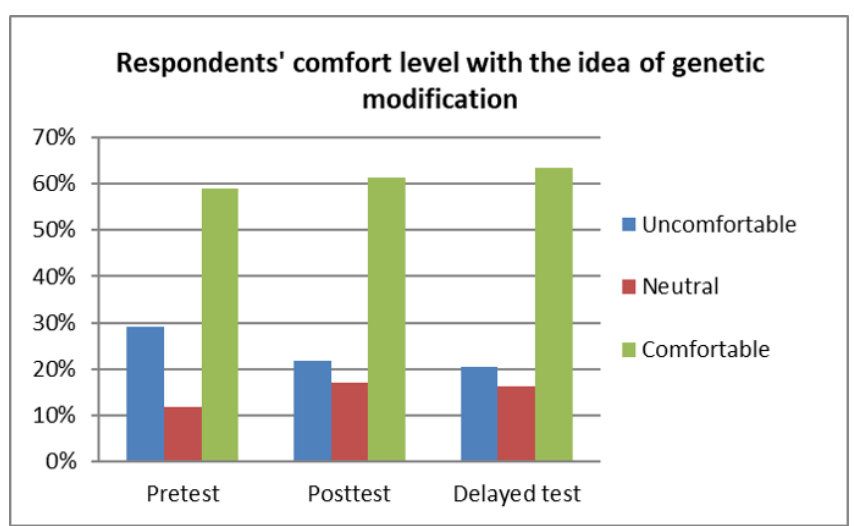

Figure 2. Respondents' comfort level with the idea of genetic modification

The number of participants who "Somewhat understand" the process of genetic modification increased from $33 \%$, before reading the informational passage, to $57 \%$ after reading it. This number stayed at $57 \%$ in the delayed survey. It was also found that participants were more comfortable with the idea of genetic modification after reading the informational passage. Figure 2 shows respondents' responses from the Likert scale question asking about their comfort level with the idea of genetic modification. Likert scale responses were combined into three groups: "Uncomfortable" (1-4 on the Likert scale), "Neutral" (5 on the Likert Scale), and "Comfortable" (6-9 on the Likert Scale). Figure 3 shows participants increased comfort level when it comes to buying items containing GMOs. In addition to being more comfortable with 
genetic modification after reading the informational passage, respondents were more likely to disagree with the statement, "I think eating GMOs is bad for my health." Participants were also slightly more likely to disagree with the statement "modifying an organism's genetic code is wrong." Fifty-two percent disagreed before reading the informational passage while $64 \%$ disagreed in the posttest. This number decreased slightly in the delayed test with 59\% disagreeing, but the neutral category increased from $16 \%$ in the posttest to $20 \%$ in the delayed test.

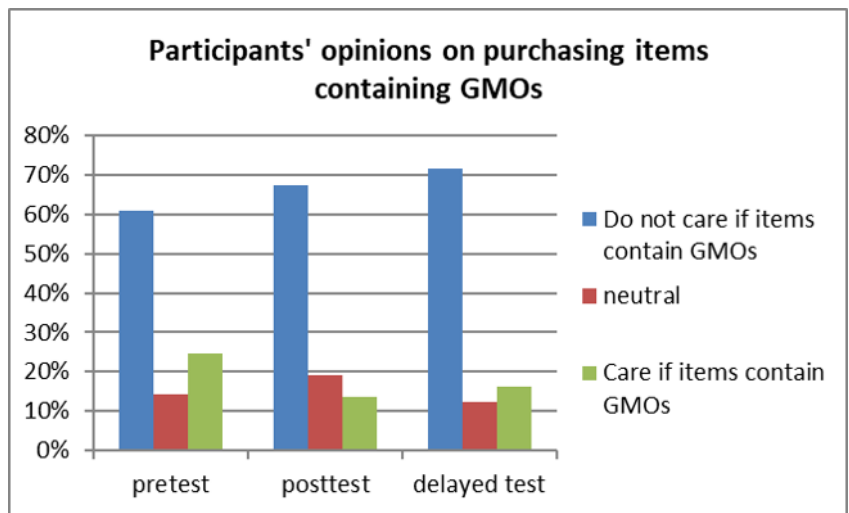

Figure 3. Participants' opinions on purchasing items containing GMOs

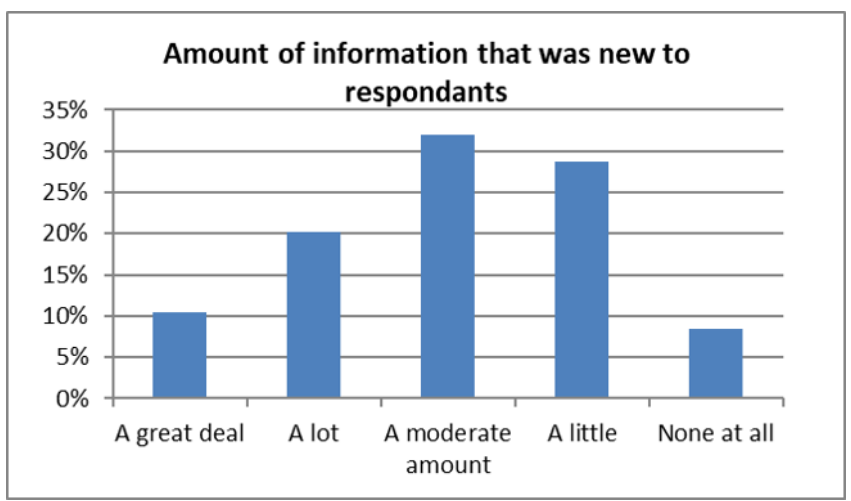

Figure 4. Amount of information in the 400-word explanation that was new

\section{Discussion}

\subsection{Opinions and Knowledge}

This study-like the previously mentioned outreach programs, HungerU, OSU K-12 outreach, and the Ranney and Dav climate-change study-showed positive results. Participants were more open and accepting of ideas after receiving information about them. All programs focus on interacting with the public to provide them with useful, scientific knowledge upon which to base their decisions. In the case of the OSU K-12 outreach program, students were more open to the concept of pursuing higher education [16]. It is important to note that the goal of this study was not to change participants' opinions but to provide them with a scientifically accurate basis of information on which to form opinions and to test whether the Ranney and Dav model of mechanistic knowledge and scientific information was applicable to other controversial scientific topics.

According to the data, mechanistic knowledge appears to be an effective way of educating the public. The data show that participants gained and retained knowledge about the process of genetic modification. Figure 1 shows that $67 \%$ of respondents did not understand the process of genetic modification on the pretest while only $43 \%$ did not understand the process on the posttest and delayed test. However, beyond our assessing the testing knowledge of participants, we also asked their opinions about GMOs. This allowed researchers to identify any correlation between increasing knowledge and increasing acceptance of GMOs. Overall, respondents appeared to be slightly more comfortable with genetic modification, as shown in Figure 2. Figure 3 shows a slight increase in the number of respondents who do not care if the items they buy contain GMOs. Changes in opinion were much less dramatic than the change in knowledge; however, there is a slight but steady trend toward a higher rate of acceptance across all opinion questions. As with the knowledge retention, the delayed survey also showed that opinions remained the same several days later. In some cases, the numbers were slightly higher or lower than were those of the delayed survey; but in most cases, opinions and knowledge were both retained after several days.

Participants received only 400 words of relevant information, yet Figure 4 shows that $92 \%$ reported that at least some of the information in the informational passage was new to them. This may indicate that participants have not received information on the process by which GMOs are made. They have most likely read or heard about the studies on health and environmental effects since these are the stories most often seen in the media; however, these results may indicate that the information provided in this passage is not readily available to the public despite its relevance.

\subsection{Information Sources}

Participants were also asked from which sources of news they get most of their information regarding GMOs. Some news sources, like social media, are often criticized for having unreliable sources and articles containing misinformation. This information allowed researchers to see where the majority of participants get their information and whether or not they believe it is accurate. This can help draw conclusions about their ability to get reliable information about a particular topic as well as help determine the types of information they may or may not be finding with their sources.

As shown in Figure 5, it was found that the most respondents reported using major internet or TV news sources such as CNN, NPR, FOX, etc. The second most popular category was social media, followed by friends and family. Respondents were then asked if they thought the source they indicated provided them with accurate information concerning GMOs. Forty percent stated "yes," while $32 \%$ stated it might or might 


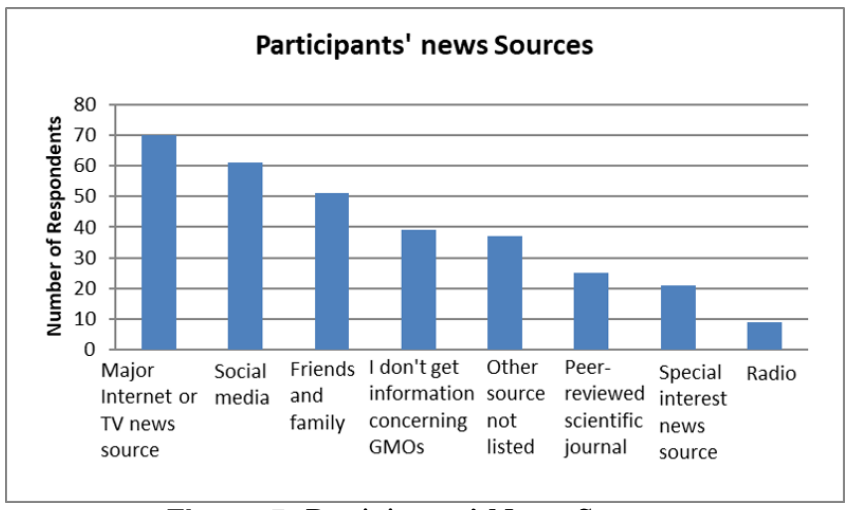

Figure 5. Participants' News Sources

not, and $28 \%$ stated that it probably did not give them accurate information. This shows that $60 \%$ of respondents have doubts about the accuracy of the information they receive. Regardless of whether or not they choose to seek out information regarding GMOs, they were then asked if they know how to obtain factually correct information. Seventy-four percent of respondents felt that they did know how to obtain such information, $14 \%$ might or might not know how, and $6 \%$ reported not knowing how.

This study found that two of the most popular sources of news regarding GMOs are notoriously unreliable and biased. As shown in Figure 5, these categories are social media and friends and family. Since such a high number of respondents stated that they were unfamiliar with at least some of the information, this may indicate a lack of readily available mechanistic education. For example, an article found on Facebook from the Underground Health Reporter states that genetically modified foods cause cancer, lung damage, and birth defects. No sources are cited, and these statements contradict the 2016 study of the National Academies of Sciences Engineering and Medicine.

\section{Limitations}

Since the survey was taken voluntarily by participants, some of them may have clicked through the survey without reading the informational passage. As discussed in the Future Research section, this problem may be minimized by using different methods of information delivery. Since the sample size included only students, many of them STEM majors, a broader range of educational backgrounds should be tested to compare results.

\section{Future Research}

This study and [11] climate change study have shown mechanistic knowledge to be a promising tool for educating the public. Future studies on mechanistic knowledge of GMOs should focus on several things. Use of other methods of explaining the mechanism could help people with different learning styles better retain information. For example, visual learners may retain knowledge better if graphics and video are used. Tactile learners may benefit from interactive games such as those found on the University of Nebraska-Lincoln Institute of Agriculture and Natural Resources Crop Watch page. Different methods of information delivery could also help reduce the likelihood of participants clicking through the survey without reading the informational passage. Next, studying a more educationally-diverse population should be studied to see if the results are similar. Also, the reason why some people still do not understand the mechanism after learning about it should be considered. Lastly, more effective methods of disseminating mechanistic knowledge to the public on a large scale should be studied.

\section{Conclusion}

Mechanistic knowledge is a promising tool for educating the public about controversial scientific issues such as genetic modification and climate change. Participants showed increased knowledge about the process of genetic modification and slightly more accepting views on GMOs. This knowledge appeared to be retained after several days, indicating long-term changes. Future research-geared toward different information-delivery techniques and outcome analysis - should focus on decreasing the percentage of participants who still do not understand the process after learning about it.

\section{Author Biography}

As a native Vermonter, Allison Haskell grew up loving the outdoors. This fueled her interest and passion for living things. She graduated from UNT as a Distinguished Honors Scholar in May 2017 with a major in biology, minor in chemistry, and certification in technical communication. While writing her thesis, she worked on an independent research project in Dr. Ayre's plant research lab. Her thesis brings together her interests in research and science communication.

Since graduation, she has hiked Vermont's 273-mile Long Trail, which runs the length of Vermont from the Massachusetts border to the Canadian border. She plans to pursue her masters and a teaching certification to continue communicating the importance of science, science education, learning, and the outdoors.

\section{References}

[1] Marta Entradas. Science and the public: The public understanding of science and its measurements. Portuguese Journal of Social Science, 14(1):71-85, 2015.

[2] Gale M Sinatra, Dorothe Kienhues, and Barbara K Hofer. Addressing challenges to public understanding of science: Epistemic cognition, motivated reasoning, and conceptual change. Educational Psychologist, 49(2):123-138, 2014.

[3] Jeffrey Brainard. Introductory science moves beyond. Chronicle of Higher Education, 54(38), 2008. 
[4] David P Cronin and Jonathan E Messemer. Elevating adult civic science literacy through a renewed citizen science paradigm. Adult Learning, 24(4):143-150, 2013.

[5] NSF. Science \& engineering indicators 2016. The National Science Board, 2016.

[6] Elizabeth Marincola. Why is public science education important? Journal of translational medicine, 4(1):7, 2006.

[7] Andrew J Wakefield, Simon H Murch, Andrew Anthony, John Linnell, DM Casson, Mohsin Malik, Mark Berelowitz, Amar P Dhillon, Michael A Thomson, Peter Harvey, et al. Retracted: Ileal-lymphoid-nodular hyperplasia, non-specific colitis, and pervasive developmental disorder in children. Lancet, 351:637-641, 1998.

[8] S Tafuri, MS Gallone, MG Cappelli, D Martinelli, $\mathrm{R}$ Prato, and $\mathrm{C}$ Germinario. Addressing the antivaccination movement and the role of hcws. Vaccine, 32(38):4860-4865, 2014.

[9] NASA. Scientific consensus: Earth's climate is warming. https://climate. nasa.gov/scientific-consensus/

NationalAcademiesofSciences. Accessed: 2017-04-01.

[10] Cary Funk and Brian Kennedy. Public views on climate change and climate scientists. Pew Research Center, 2016.

[11] Michael Andrew Ranney and Dav Clark. Climate change conceptual change: Scientific information can transform attitudes. Topics in Cognitive Science, 8(1):49-75, 2016.

[12] Pew. Major gaps between the public, scientists on key issues. Pew Research Center, 2015.

[13] Ruth Mbabazi, Hashini Galhena Dissanayake, Joe Guenthner, and Karim Maredia. Perception of international stakeholders on genetically modified organisms (gmos). Asian Biotechnology and Development Review, 18(2):5157, 2016.

[14] Sarah Lively. The abcs and ntbs of gmos: The great european union-united states trade debate-do european restrictions on the trade of genetically modified organisms violate internaitonal trade law. Nw. J. Int'l L. \& Bus., 23:239, 2002.

[15] B Elijah Carter, Caitlin C Conn, and Jason R Wiles. Concern about hunger may increase receptivity to gmos. Trends in plant science, 21(7):539-541, 2016.

[16] Sujaya Rao, Devora Shamah, and Ryan Collay. Meaningful involvement of science undergraduates in k-12 outreach. Journal of College Science Teaching, 36(6):54, 2007.

[17] NASEM. Genetically Engineered Crops: Experiences and Prospects. The National Academies Press, 2016.
[18] O Arnold, M Teschke, J Walther, LN Lamprey, H Lenz, FG Kaiser, and MA Ranney. Increasing global warming knowledge and acceptance by directly web-disseminating scientific information. 15th Annual Education Research Day. Berkeley, 2015.

\section{Appendix A}

The following text is the 400-word mechanistic, informational passage read by participants.

Please read the following passage.

Genetic modification began 10,000 years ago when humans first domesticated crops. Our ancestors farmed teosinte, the ancestor of corn. Each year, they replanted the seeds from the best corn to improve the crop. Over many years, they transformed teosinte into something we recognize today as corn. Corn is much larger, sweeter, softer, and looks very different from its ancient ancestor. This process is an ancient method of genetic modification called artificial selection, also known as traditional plant breeding.

Modern biotechnology gives us the ability to directly insert a gene into a crop. This technology speeds up the modification process as well as increases the variety of traits that can be produced. For example, corn is commonly genetically modified for insect resistance (Bt corn). A bacterial gene that is lethal only to a small range of insects is inserted into the corn's genome. Once the gene is in, the corn will produce a toxin that kills specific insects. This gene does not affect humans because the toxin only works under the specific conditions found in the gut of target insects. To make Bt corn, there are five major steps. 1) The genetic code from the organism with the desired gene is sequenced. 2) The specific gene of interest is isolated. 3) The isolated gene is modified for optimal function in the new host. 4) The gene is inserted in the new host using a bacterium that naturally transfers genes from its own genome to the plant's genome. Lastly, 5) the plant is bred to produce more insect resistant plants. These plants are now transgenic because they contain a bacterial gene for insect resistance. Insect resistant plants are beneficial because they decrease the need for pesticides. Another example of a GMO is golden rice, which has been genetically modified to produce more beta-carotene, a precursor to vitamin A. In poor countries, increased beta-carotene consumption can help prevent blindness and death in children.

Whether a crop is traditionally bred or genetically modified, it must undergo testing to determine if it is safe for consumption. Even traditionally bred plants are capable of producing harmful toxins. For example, several types of potatoes are banned from the market due to high concentrations of toxins. Currently, no reliable studies show a strong relationship between GMO consumption and health problems. Studies show that consuming GMOs is as safe as consuming traditionally bred crops.

Summary: Humans have been genetically modifying plants for thousands of years through traditional breeding. 
Modern biotechnology allows us to directly insert a gene into a new crop using five steps. All crops for human consumption must undergo testing for safety. GMOs are comparably safe to traditionally bred plants and have many benefits.

Shorter Summary: Modern biotechnology allows direct insertion of a gene into a crop, which is faster than traditional breeding. Since all crops must undergo testing, GMO health risks are comparable to traditionally bred plants. GMOs also have many benefits.

\section{Appendix B}

The following is the rubric used to grade free response questions.

- If respondent answered the pre-test question but not the post-test question, assume they did not gain or lose any knowledge and assign the same grade as the pre-test question.

- If the respondent did not answer the pre-test or pre and post-test question, assume they do not know and assign a 1 . 


\begin{tabular}{|c|c|c|}
\hline $\begin{array}{r}\text { \# } \\
\text { Assigned }\end{array}$ & Correctness & Keywords in Response \\
\hline 1 & $\begin{array}{l}\text { probably does not know how } \\
\text { GMOs are made }\end{array}$ & $\begin{array}{l}\quad \text { no answer, only answered } \\
\text { why, I don't know, using } \\
\text { chemicals, injecting hormones, } \\
\text { made in labs, improving trait, } \\
\text { putting in features }\end{array}$ \\
\hline 2 & made $\quad$ somewhat knows how GMOs are & $\begin{array}{l}\text { only selective/cross } \\
\text { breeding mentioned, } \\
\text { CRISPER/CAS } 9 \text { only, modify } \\
\text { genetic information, adding } \\
\text { features }\end{array}$ \\
\hline 3 & $\begin{array}{l}\text { probably knows how GMOs are } \\
\text { made }\end{array}$ & $\begin{array}{l}\text { adding genes/DNA, DNA } \\
\text { insertion, gene splicing/piecing, } \\
\text { selective breeding and genetic } \\
\text { manipulation, genes transferred } \\
\text { from one organism to another, } \\
\text { modifying genes, gene } \\
\text { manipulation, recombinant DNA, } \\
\text { altering DNA }\end{array}$ \\
\hline 4 & $\begin{array}{l}\text { definitely know how GMOs are } \\
\text { made }\end{array}$ & $\begin{array}{l}\text { states specific steps of } \\
\text { genetic modification process }\end{array}$ \\
\hline
\end{tabular}

Figure 6. Question Grading Rubric 